\section{NATUREZA E HISTÓRIA NA FILOSOFIA IDEALISTA DE HEGEL: INDÍCIOS ONTOLÓGICOS PARA A COMPREENSÃO DO SER E DA CORPOREIDADE HUMANA}

\author{
NATURE AND HISTORY IN HEGEL'S IDEALIST PHILOSOPHY: \\ ONTOLOGICAL CLUES FOR UNDERSTANDING HUMAN BEING AND \\ CORPOREALITY C
}

NATURALEZA E HISTORIA EN LA FILOSOFÍA IDEALISTA DE HEGEL: INDICIOS ONTOLÓGICOS PARA LA COMPRENSIÓN DEL SER Y DE LA CORPOREIDAD HUMANA C

doi) https://doi.org/10.22456/1982-8918.109297

Marcel Farias de Sousa* <nichscene@yahoo.com>

Edson Marcelo Hungaro** <mhungaro@unb.br>

\footnotetext{
*Universidade Federal de Goiás. Goiânia, GO, Brasil.

**Universidade de Brasília. Brasília, DF, Brasil.
}

Recebido em: 18 nov. 2021 Aprovado em: 13 jul. 2021 Publicado em: 28 ago. 2021

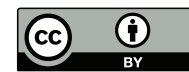

Este é um artigo publicado sob a licença Creative Commons Atribuição 4.0 Internacional (CC BY 4.0).

elSSN: $1982-8918$ 


\section{INTRODUÇÃO}

O debate sobre o corpo na Educação Física brasileira - no contexto do chamado "Movimento Renovador" de caráter crítico e progressista (CASTELLANI FILHO, 2019) assentado naquilo que foi denominado com um "projeto de intenção de ruptura" (HUNGARO, 2010) - foi marcado pelo questionamento do cientificismo de viés positivista ancorado numa complicada relação com as ciências que reduziam o corpo às suas determinações naturais - circunscrevendo o entendimento às concepções mecanicistas e deterministas sobre a natureza, sobre o ser humano e a relação entre ambos.

No contexto do "Movimento Renovador", então, diferentes aportes teóricometodológicos contribuíram para significativas empreitadas de caráter teórico a fim de conseguir, no plano teórico, superação das dicotomias, dos dualismos e das concepções mecanicistas hegemônicas na interpretação da questão do corpo, dentro da área da Educação Física.

Sob a influência da filosofia (especialmente do pensamento fenomenológico) e da Antropologia (especialmente em seu viés interpretativo) a esfera da cultura foi alçada como principal conceito para o entendimento das diversas perspectivas presentes no debate da área, não só, mas especialmente no que tange à compreensão de corpo. Houve a valorização do aspecto simbólico da conduta do ser humano como aporte fundamental para a constituição da identidade da área (DAÓLIO, 2004). O debate das determinações da Educação Física teria, para Daólio, a questão da cultura como um elemento central e boa parte das interpretações presentes sofreriam de um problema de fundo: a separação entre natureza e cultura, herdada da maneira moderna de pensar. Esse suposto, em larga medida, conduziu a reflexão da área à aproximação e apropriação de determinados referenciais teórico-metodológicos das ciências sociais e humanas, com destaque e predominância de Clifford Geertz, nas sistematizações de viés antropológico, e Maurice Merleau-Ponty e Michel Foucault, nas sistematizações de viés epistemológico (MOREIRA, 1995; ZOBOLI, 2007; NÓBREGA, 2009, entre outros).

Entre outras lacunas, uma é facilmente notada: as elaborações efetivadas a partir da lógica dialética (hegeliana e marxiana). Tal tradição que fez avançar consideravelmente a compreensão das relações entre natureza e história (ou natureza e cultura) são tratadas e criticadas numa tendência de homogeneização da filosofia iluminista e moderna compreendidas, em grande medida, como se operassem cindindo natureza e cultura, e o dualismo ser humano-corpo (sujeito da cultura) e natureza fosse uma espécie de desdobramento dessa cisão.

Como consequência, tem-se certa desconsideração com alguns pensadores modernos e o reconhecimento do estatuto ontológico da natureza ${ }^{1}$ na formação

\footnotetext{
1 Este é um ponto de debate ainda pouco explorado na Educação Física e que merece uma maior atenção. Encontram-se posições distintas quanto ao estatuto ontológico da natureza conforme é observado no trabalho de Bassani e Vaz (2011), que, a partir de Theodor Adorno e Susan Buck-Morss, afirmam que a natureza ou a história como premissa ontológica leva à perda dos significados multidimensionais de cada conceito, como também busca problematizar o conceito de segunda natureza encontrado em alguns autores na filosofia alemã (nas obras iniciais de Lukács, Walter Benjamim e Adorno). Assim também se tem na obra de Jocimar Daólio a afirmação de uma natureza humana que seja uma natureza cultural (DAÓLIO, 1995). Em contrapartida, também se encontram trabalhos, fundamentados na ontologia marxiana-lukasciana, em que a natureza (dimensões inorgânica e orgânica) é uma esfera ontológica do ser social (ORTIGARA, 2002; HUNGARO, 2008; SILVA, 2017; entre outros) com a qual o ser humano (singular e genérico) encontra-se em constante processo sociometabólico e da qual emerge uma segunda natureza, a constituição da generidade humana.
} 
humana (nesse período, iniciado pela dialética hegeliana e, posteriormente, desenvolvido na teoria social de Marx).

O presente texto - que é um recorte de uma investigação mais ampla que teve por objeto as contribuições da teoria social de Marx para a compreensão do corpo - é uma resposta à equivocada compreensão de que todo o pensamento moderno operou com a separação entre natureza e história (cultura). Apoiados em Lukács (2010; 2012; 2013), supomos que Marx empreendeu significativos esforços a fim de compreender o que os seres são num contexto particular: o das relações sociais de produção na ordem social burguesa. Essa problemática o conduziu a refletir sobre esse ser (humano) que é natureza e, ao mesmo tempo, transforma a natureza por meio de sua atividade consciente. Como resultado, portanto, nos fez herdeiros de uma explicação acerca do que somos nessa determinada ordem social (a burguesa), mas, ao mesmo tempo, explicitou elementos histórico-universais dos seres.

Ao notar que o aspecto distintivo (essencial) dos seres humanos é o fato de eles se objetivarem e sua objetivação fundante é o trabalho, a transformação intencional do ser humano sobre a natureza, Marx acabou por nos indicar algo que é essencial nos seres humanos: são seres que se objetivam. Assim, seja no capitalismo, no feudalismo, na antiguidade clássica ou nas sociedades futuras, esse aspecto distintivo estará presente: a capacidade de objetivar sua consciência. Desse intercâmbio entre a natureza e os seres humanos (que também são natureza), outras formas de objetivação são constituídas (a arte, a ciência e a linguagem).

Uma reflexão inicial, então, demonstra que ser humano (corpo) é natureza e história (cultura) ao mesmo tempo. Com isso, a compreensão da questão do corpo, na inspiração teórica adotada, exigiu-nos a investigação sobre as relações entre natureza e história. Precisávamos conhecer o processo de constituição do ser em relação às esferas inorgânicas, orgânicas e as sociais (LUKÁCS, 2010; 2012; 2013).

Tal questão de fundo recebeu a atenção da filosofia, desde a antiguidade, porém, para os limites da investigação pretendida, ativemo-nos à modernidade e, especialmente, aos autores cuja atenção recaiu sobre os elementos ontológicos.

Para Lukács (2012), embora a contribuição de Kant tivesse sido significativa, não apresentou uma resolução satisfatória para a (suposta) antinomia entre natureza e história. Para ele, o percurso do reconhecimento ontológico da natureza ganha maior solidez - ainda que sob viés idealista - na filosofia de Hegel.

Inicialmente, portanto, o estudo centrou-se na revisão sobre o desenvolvimento histórico-lógico das categorias da natureza e da história no sistema filosófico de Georg W. F. Hegel. Para isso, recorreu-se à leitura de algumas das obras de Hegel: Ciência da Lógica (CdL), a Enciclopédia das Ciências Filosóficas em Compêndio (EdCF), particularmente em seu segundo volume sobre a Filosofia da Natureza (FdN).

Para a interpretação da obra hegeliana, serviu de apoio a análise de Marx presente nos Manuscritos Econômico-Filosóficos (2010) e os rigorosos estudos de Lukács nos livros O Jovem Hegel (LUKÁCS, 2018) e no primeiro volume de Para uma ontologia do ser social (LUKÁCS, 2012; 2013). Para Lukács, no pensamento hegeliano se teve o maior desenvolvimento da estruturação da lógica dialética 
enquanto método de investigação. Além disso, também se encontram elementos para uma autêntica ontologia como para uma falsa ontologia (MARX, 2010; LUKÁCS, 2012; LUKÁCS, 2018; BARATA-MOURA, 2012; RANIERI, 2011).

\section{ALGUMAS NOTAS SOBRE O IDEALISMO OBJETIVO DE HEGEL}

O estudo da filosofia de Hegel é fundamental para entender o desenvolvimento dos conceitos de natureza e história - a partir do debate sobre a razão e liberdade.

Hegel teceu críticas a Kant, especialmente, quanto aos traços irracionalistas de seu pensamento expressos na afirmação da "coisa em si", do noumenum; à filosofia idealista da época; às concepções de natureza e de ser desenvolvidas pelos filósofos contratualistas; e ao materialismo mecanicista (francês). Ou seja, enfrentou o caldo cultural de sua época.

O sistema hegeliano, conforme Lukács (2018), marca a transição do idealismo subjetivo para o idealismo objetivo: a interiorização da consciência - originada na própria consciência - é posto em movimento, o processo objetivo do sujeito. A partir da transformação da substância em sujeito se tem a realização do sujeito-objeto idêntico. Assim, o ser é Ideia e é realidade.

Lukács (2018) observa que a transição do idealismo subjetivo ao idealismo objetivo é "[...] uma questão de posição filosófica diante da realidade do ser, que existe independentemente da consciência" (LUKÁCS, 2018, p. 312).

Apesar disso, sempre segundo Lukács, as formas de idealismo objetivo presentes no pensamento hegeliano ainda não passariam de pseudossolução para lidar com o problema da realidade objetiva.

$\mathrm{Na}$ primeira forma hegeliana, a realidade empírica aparece como produto do Setzens (pôr) "[...] levado a cabo pelo sujeito filosófico [...]" e que, além disso se encontra outra realidade não posta - uma realidade que independe da consciência humana, a realidade religiosa. Tal compreensão demonstra o caráter extremamente idealista em que se tem a unidade do princípio subjetivo com o princípio objetivo, "[...] a contraposição de homem e mundo na unidade de homem e Deus" (LUKÁCS, 2018 , p. 313). Por esta forma, surge uma pseudorrealidade mística que se torna via possível para o surgimento de irracionalismos que podem ser preenchidos com "[...] todo tipo de conteúdo reacionário" (LUKÁCS, 2018, p. 313).

O segundo tipo de idealismo objetivo em Hegel se encontra na Fenomenologia do Espírito (FdE). A explicitação do mundo como autoprodução e autoconhecimento do espírito. A realidade objetiva é apenas uma forma de seus diversos estágios de exteriorização (Entäußerung). Lukács afirma que, aqui, são trazidos elementos significativos, embora limitados, para a compreensão de uma dialética do desenvolvimento humano, da legalidade da natureza e da história em sentido mais progressivo (LUKÁCS, 2018). Tais elementos foram, por Marx, "postos sobre os pés" no sentido materialista.

Entende-se que Hegel abandonou a divergente representação fundamental do Iluminismo acerca da unidade entre razão e natureza, mas sem sacrificar a 
concepção desta corrente de que o reino da razão é um produto peculiar dos próprios seres humanos, tais como estes são na realidade. Chauí (2000) explica que, enquanto por uma perspectiva (objetivista), os empiristas e inatistas acreditavam que o conhecimento racional das coisas provinha e derivava das próprias coisas e que a verdade seria a correspondência entre a coisa e a ideia da coisa, por outra perspectiva (subjetivista), o conhecimento racional dependeria exclusivamente do sujeito do conhecimento, das estruturas da sensibilidade e do entendimento, conforme elaborou Kant.

A razão, para Hegel, foi compreendida de forma mais ampliada: não é exclusivamente objetiva ou subjetiva, mas é a unidade destas esferas que estabelece a relação necessária entre as leis do pensamento e as leis do real, na qual caberia nela, todas as criações do espírito humano na história como a arte, as religiões e os sistemas políticos (CHAUÍ, 2000; MENESES, 2003; ANDERY et al., 2012). Para Hegel, como se nota, na evocação racional se encontram também as paixões humanas. Não concebe a realidade terrena humana contendo elementos incognoscíveis, pelo contrário, aprofunda a análise sobre ela e torna a razão algo mais fundamentado no concreto (LUKÁCS, 2012).

O sistema lógico de Hegel demonstra tanto o caminho que a consciência percorre para o conhecimento quanto a passagem da subjetividade à objetividade - que se unem, posteriormente, na Ideia, a saber: Ciência, Ser, Essência, Conceito (INWOOD, 1997; RANIERI, 2011; HEGEL, 2012; HEGEL, 2018). Assim, segue-se uma breve descrição do que seja a Ideia, visto a sua relação com a concepção de Vida.

A Ideia em Hegel é a um só tempo o em-si e o para-si. É, também, essencialmente objeto da lógica e está associada à junção entre a subjetividade, objetividade e o conceito, unidade entre a percepção e objetividade. Ou seja, a Ideia deve valer como objetividade adequada do conceito, como unidade do conceito e da realidade. É a plena realização de um conceito, é o universal cuja manifestação está presente na particularidade do conceito, mas que não é sinônimo de transcendência, pois abarca movimento (para Hegel, a Ideia tem sua realidade na objetividade, não é um ser abstrato, mas um devir) (RANIERI, 2011; HEGEL, 2012; HEGEL, 2018).

"A ideia é o conceito adequado, o verdadeiro [num sentido] objetivo ou o verdadeiro enquanto tal" (HEGEL, 2018, p. 237). Tal elaboração parte de um diálogo direto com a conceituação kantiana, para qual a ideia era postulada como uma totalidade projetada, como algo necessário, mas como "[...] a meta que seria preciso estabelecer como modelo para um máximo e da qual seria preciso aproximar o estado de efetividade com cada vez mais esforço" (HEGEL, 2018, p. 238). Hegel, então, afirma que a Ideia é a unidade do conceito e da objetividade e não apenas uma meta projetada.

\section{VIDA: DO CONCEITO À IDEIA, UM PERCURSO PARA UMA FILOSOFIA DA NATUREZA E CORPOREIDADE EM HEGEL}

A Vida, segundo Hegel, enquanto Ideia, é algo tão concreto e real que por si só, parece não corresponder ao âmbito da lógica. Mas esse aspecto aparente é 
questionado pelo autor uma vez que, assim como a lógica pura lida ${ }^{2}$ com ideias como a de verdade absoluta e que exige um exercício, um procedimento que é de essencialmente conhecer -, a Vida (como ideia imediata) pode ser compreendida como pensamento e conceito que se apresentam subjetivamente sob as formas psicológicas e antropológicas, entre outras.

A ideia de Vida, inicialmente, é considerada e conhecida em sua imediatez (enquanto pressuposição) pelo próprio conceito. Ou seja, o conceito leva a conceber a Vida nesta determinação primeira para que tal consideração não seja vazia ou carente. Hegel procura, assim, mostrar que a Vida em seu sistema lógico-filosófico teria um "trato" distinto das demais ciências não filosóficas.

Antes de seguir, é importante observar que a Vida natural, considerada e conhecida pelas outras ciências (não filosóficas), se difere da lógica da Vida no pensamento hegeliano, uma vez que ela tem associação e vínculo com o Espírito. Assumindo essa aproximação, tem-se uma conceituação mais ampla daquela encontrada nas outras ciências. A Vida na lógica (das ciências e da filosofia) será considerada, conceituada e estruturada no interior das ciências reais e na filosofia da natureza.

Ora, para a reflexão acerca da questão do corpo, essa elaboração hegeliana é de fundamental importância, pois a compreensão da Vida, em sua articulação entre natureza e história, em unidade, aponta caminhos para a superação da dicotomia entre corpo e espírito. Traz uma compreensão mais saturada de determinações. Tradicionalmente, a Vida aparece em parte como oposta ao espírito (nas ciências não filosóficas): o espírito não é algo natural e aparece em oposição à natureza.

Diante a consideração sobre a unidade da Vida com o espírito, a Vida (natural) é em parte meio para o espírito (o que o põe em contraposição à Vida natural) e, por sua vez, o espírito é um indivíduo vivo e a Vida é o seu corpo. Esta unidade do espírito com sua corporeidade-corporalidade é gerada dele mesmo (do espírito) como ideal.

Hegel, porém, ressalta a contradição deste raciocínio e expõe que, em sua lógica, a Vida assume uma relação dialética com o espírito:

\begin{abstract}
A Vida tem [...], como Vida natural e como está em relação com o espírito, uma determinidade de sua exterioridade, lá por meio de suas pressuposições, que são outras figurações da natureza, mas aqui através dos fins e da atividade do espírito. A ideia de Vida por si é livre daquela objetividade pressuposta e condicionante, bem como da relação com esta subjetividade (HEGEL, 2018, p. 247).
\end{abstract}

Seguindo o processo lógico de constituição da conceituação da Vida, Hegel expõe, que ela tem de ser considerada em si e para si, como absoluta universalidade. Acrescenta-se a isso a noção de que entre a natureza e o espírito aparece um novo constructo que será chamado por Hegel de Alma. Este conceito é mais bem desenvolvido quando o autor explicita os três momentos conceituais da Vida organizados na articulação entre as categorias singularidade-particularidadeuniversalidade (BAVARESCO, 2010).

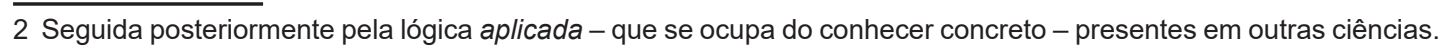




\subsection{A VIDA ENQUANTO INDIVÍDUO VIVO}

O indivíduo vivo é a singularidade. É definido por Hegel como alma, mas entendendo como o conceito em si mesma, como o princípio que inicia e move a si mesmo. Noutras palavras, entende-se alma como o equivalente a psíquico, ou seja, aquilo que esteja no conjunto de fenômenos mentais no ser humano. Hegel observa: "O ser vivo tem a corporeidade, inicialmente, como a realidade que é imediatamente idêntica ao conceito; com isto, a alma em geral tem a corporeidade por natureza" (HEGEL, 2018, p. 250).

Importante observar nesta passagem que a noção de indivíduo não aparece desconectada da corporeidade enquanto um organismo natural. Segundo Bavaresco (2010), esta corporeidade do indivíduo vivo corresponde a articulação silogística almacorpo-objetividade exterior. O corpo-organismo é a objetividade viva do indivíduo que necessita ser animada pelo conceito que possui como determinação a universalidade (a própria objetividade viva do indivíduo), a particularidade e a singularidade (HEGEL, 2018; BAVARESCO, 2010).

\subsection{A VIDA COMO PROCESSO VITAL}

O indivíduo, em seu pressuposto originário, entra em tensão consigo mesmo para se configurar, mas também se põe como sujeito do processo perante o mundo objetivo pressuposto. Entende-se que o mundo é o negativo (a negação entendida como o momento necessário da dialética que tensiona o Ser em sua relação com a exterioridade) e não um autossubsistente (trazido originariamente). $\mathrm{O}$ indivíduo vivo se postará sobre forma de tensão direta e contínua com esta exterioridade que será, por conseguinte, tomada novamente na consciência.

Neste sentido, o indivíduo vivo se relaciona com a exterioridade. O mundo exterior, como uma particularidade iniciada pela carência-necessidade. Esta carência-necessidade demonstra, ao mesmo tempo, a autonomia do indivíduo e a sua dependência do ambiente, ou seja, no conceito, o indivíduo se encontra cindido, o que expõe a contradição vivida e sentida por este como dor, a contradição é uma existência efetiva na dor do ser vivo. A objetividade do mundo torna-se um objeto para o indivíduo que, através do processo é capaz de assimilar o objeto na sua interioridade. A Vida, então, se realiza pelo compreender de si mesma, como fim em si mesma, por meio dos graus de autossentimento até alcançar a consciência de sua universalidade genérica (HEGEL, 2018; BAVARESCO, 2010).

\subsection{A VIDA NO PROCESSO DE GÊNERO}

Em linha gerais, segundo Bavaresco (2010), o gênero é o momento em que se tem o retorno, de forma plena, do indivíduo a si mesmo. Retorno este ocasionado pela capacidade de se produzir e reproduzir do indivíduo. Neste sentido, "[...] o indivíduo genérico carrega em si toda a objetividade como uma totalidade, por isso é capaz de reconhecer o outro indivíduo. O indivíduo genérico se expressa sob a forma da duplicação do indivíduo" (BAVARESCO, 2010, p. 24). O gênero é uma identidade 
universal que se organiza nas gerações que se engendram e se propagam como viventes (BAVARESCO, 2010).

Para Hegel, o processo do gênero no qual os indivíduos singulares suprassumem ${ }^{3}$ sua existência indiferente, imediata, uns nos outros e morrem nessa unidade negativa, tem como outro lado do seu produto o gênero realizado que se pôs idêntico ao conceito. No gênero, sucumbem as singularidades isoladas da Vida individual, na qual morre a imediatidade da individualidade e se tem o surgir do espírito (HEGEL, 2018).

Assim, conforme exposto anteriormente, todo o desenvolvimento lógico sobre a categoria Vida em Hegel trata do entendimento desta como determinação natural do ser sensível. Ele vê a Ideia absoluta como mediação da lógica, da natureza e do espírito. Na natureza, a Ideia Absoluta se exterioriza, pois ela está parcialmente realizada como ideia lógica, mas esta precisa sair dela e ir para uma outra esfera (HEGEL, 2018). Nas palavras de Hegel: "Na medida em que a ideia se põe como unidade absoluta do puro conceito e de sua realidade, com isso, recolhe-se na imediatidade do ser, assim ela como a totalidade está na forma - natureza" (HEGEL, 2018, p. 333).

\section{FILOSOFIA DA NATUREZA E HISTÓRIA EM HEGEL}

Quando se trata especificamente da obra EdCF (2012a) e do segundo volume que versa sobre a Filosofia da Natureza, Hegel trata da Vida não somente como determinação lógica do ser, mas como determinação do ser sensível, ou seja, da Ideia em sua exteriorização. Hegel continua a operação de sua lógica no trato e passagem do Ser à Ideia e da Ideia Lógica à natureza, focando na análise da Ideia da natureza enquanto princípio universal e sua determinação no princípio subsidiário do organismo vivo que ocorre através dos três processos que se diferenciam do único silogismo concreto da Vida como ser-aí imediato da razão (HEGEL, 1997; 2012b; BAVARESCO, 2010).

A relação entre a Ideia Lógica e a natureza iniciada ao final da $C d L$ e que avança na Filosofia da Natureza é, segundo Inwood (1997), uma questão controversa:

[...] ao final da CdL, a Ideia Lógica liberta-se (sich...entlässt "'solta-se') ou, por uma livre decisão (Entschluss), determina-se como ideia EXTERNA ou INTUITIVA. [...] essa transição da lógica para a natureza é muito diferente das transições (Übergange, de übergehen, 'passar para o outro lado, transpor') que ligam categorias dentro da Lógica. Por conseguinte, a ideia lógica não se converte imediatamente em VIDA, o estágio da natureza que é a mais óbvia contraparte para a suprema fase da lógica, mas retorna, por assim dizer, ao seu começo e torna-se o puro do ser de ESPAÇO. Passa, então pelas fases da MECÂNICA (espaço e tempo, matéria e movimento, mecânica absoluta, isto é, o sistema planetário), física (passando da luz para os processos químicos) e física orgânica (a Terra como um organismo e a Vida orgânica) (INWOOD, 1997, p. 232).

\footnotetext{
3 Acerca da tradução do termo Aufheben e Aufhebung para suprassumir e suprassunção. Aqui, Aufhebung fo traduzido para suprassunção por se tratar do termo presente já na obra madura de Hegel e apresentar o caráter progressivo de uma ação que, ao mesmo tempo, realiza um negar ou suprimir [sumir], um conservar [assumir] e um elevar [supra+assumir]. As outras opções (superar, remover, suspender) estão afetadas por unilateralidades que originariam uma compreensão desviante do sentido original utilizado por Hegel (HEGEL, 2018).
} 
Tais processos sucessivos na lógica que opera as passagens não significam que a natureza possua uma história: na concepção hegeliana, o fóssil nunca está vivo, por exemplo. O que se tem na natureza são fenômenos que se desenvolvem de formas cíclicas e repetitivas. Vale ressaltar que a história, para Hegel, tem uma conceituação mais ampla que aquelas presentes em sua época, tais como: o entendimento sobre a sequência de eventos históricos e o estudo e relato destes eventos. Para Hegel, a história "[...] é o modo de ser da razão e da verdade, o modo de ser dos seres humanos e que, portanto, somos seres históricos" (CHAUí, 2000, p. 59). Ou seja, a história é obra da própria razão.

Na investigação de Lukács (2018) sobre Hegel - que analisa o desenvolvimento do sistema filosófico nos escritos da juventude de Hegel, até o momento da elaboração e publicação da $F d E$ - demonstra-se que a concepção de história hegeliana avança em relação as concepções presentes na filosofia alemã, pois há um trato dessa categoria em diferentes momentos de sua trajetória. Destaca, ainda, que o elemento principal é a conexão entre o tempo e a filosofia que fundamenta a concepção do filósofo sobre o desenvolvimento humano.

A consciência, que é em si e a si se eleva, se objetiva. É um produto da evolução global da humanidade - ainda que a própria consciência não tenha compreendido tal evolução como história, mas como uma série de destinos humanos que têm em si uma ordem objetiva. Somente quando o sujeito percorre o processo evolutivo compreende a objetividade real que é a história efetiva, que não deixa de ser um produto consciente da atividade da humanidade. Quando o próprio sujeito conhece a sua história efetiva, quando a consciência se autoconhece, tem-se então a possibilidade de percorrer toda a história de forma retrospectiva, o que nos permite a apreensão dos caminhos que a humanidade trilhou, as leis gerais que a regularam, inclusive as econômicas. A realização desse processo se dará no desenvolvimento do espírito absoluto (na arte, religião e filosofia-razão) (LUKÁCS, 2018).

Em suas obras posteriores, Hegel mudou sua concepção, mantendo os princípios da relação entre a história universal e a filosofia, mas também desenvolvendo a categoria da astúcia da razão ${ }^{4}$, por meio da constatação de que a razão pode ser a governadora da história. Sobre a astúcia da razão, Lukács afirma que esta expressão ascende à condição de categoria central a partir do reconhecimento do trabalho como categoria fundante, pois expressa as relações fundamentais entre teleologia e causalidade:

Hegel vê no trabalho a mobilização das forças da natureza independentemente de suas tendências naturais, até mesmo contra suas tendências naturais, com base no conhecimento da causalidade nelas presente e de sua utilização pela teleologia do trabalho concreto. (LUKÁCS, 2018, p. 28).

Mesmo que haja também períodos distintos de desenvolvimento de suas considerações com a concepção de história, conforme alerta Lukács (2018), é

4 Astúcia da razão "[...] significa que os homens de fato fazem eles mesmos sua história, que o motor real dos acontecimentos históricos reside nas paixões humanas, em suas aspirações individuais, egoístas, mas que da totalidade dessas paixões individuais resulta, em termos de tendência principal, algo diferente do que desejam e almejam os homens em ação; que esse diferente, todavia, de modo nenhum representa algo casual, mas que exatamente nele aparece a legalidade da história, a 'razão na história', o 'espírito' - segundo expressões de Hegel” (LUKÁCS, 2018, p. 473). 
possível, apoiados em Inwood (1997), uma síntese: Hegel era cético quanto às pretensões dos historiadores filosóficos em fornecer informação sobre o começo ou o fim da história, pois, para ele, a história termina com o presente (autoconsciência) e quando se realiza a plena liberdade - ainda que admita na história presente a ocorrência de novos eventos.

\section{CONSIDERAÇÕES FINAIS: ACERCA DO SER E DA CORPOREIDADE NA FILOSOFIA HEGELIANA}

A partir do estudo desenvolvido, foi possível identificar que a filosofia hegeliana representa um encaminhamento de solução da relação entre natureza e história. Vimos que em sua compreensão de Ideia não é uma simples identificação mecânica da natureza e suas propriedades físicas. Hegel trata da natureza no interior de um processo lógico-dialético em que se opera o reconhecimento de uma exterioridade ao Ser - que se exterioriza e sai de sua imediatidade, confronta-se com a negatividade necessária para a constituição da identidade, do fundamento e do conceito. Porém, tal processo não é um simples caminho lógico formal. Trata-se de processo que já é algo dado na própria interioridade (na essência do próprio ser ou objeto).

Assim, nessa processualidade que resulta no estranhamento do homem quanto à exterioridade - reconhecida na diferença entre ser-estranho (Fremsein) e ser-estranhado (Entfremdetsein) e, assim, a natureza é estranhada -, observa-se que em Hegel já se encontra uma distinção significativa da compreensão das ciências naturais e do materialismo mecanicista que operam com a noção de que há uma natureza estranhada e indiferente ao ponto de vista humano (LUKÁCS, 2012). Este sentido é um importante apanhado na lógica hegeliana que traz uma determinação ontológica da natureza.

Outros elementos significativos para o entendimento da questão do corpo foram encontrados nos textos hegelianos ( $\mathrm{Na} F d N$, na $E d C F$ ) e nas análises de Lukács e Bavaresco. Além de trazerem elementos que, ao adensarem a compreensão sobre a natureza, trouxeram reflexões pertinentes para se pensar o corpo a partir da passagem da consciência sensível à objetividade e da unidade da ideia lógica com a natureza - uma relação esta que se torna conhecida a partir do movimento do abstrato para o concreto.

Se é afirmado na CdL, a partir da conceituação sobre a Vida, que a corporeidade-corporalidade é dada como o imediato da alma (do indivíduo vivo) e, por consequência, é para a alma, sua natureza, na $F d N$, ao tratar da relação da natureza com a exterioridade, Hegel entende-a como uma "[...] contradição exterior" (HEGEL, 2012b, p. 11). Mas, não exterior ao ser, pois nossos corpos (organismo vivo e natural) são constituintes do indivíduo. Hegel não considera que a natureza seja exterior ao homem, seja exterior ao corpo, visto que este é uma parcela da natureza (BAVARESCO, 2010).

Ao mesmo tempo, em Hegel, a natureza é uma contradição que não se resolve, pois se encontra "[...] entre a necessidade do conceito e da contingência dela mesma" (BAVARESCO, 2010, p. 27). Isso ocorre pelo fato de a natureza ter como 
determinação fundamental a exterioridade que aparece à consciência e à Ideia como negativo. Assim, a natureza se encontra entregue ao acaso e à necessidade, aparece sem uma interioridade autônoma que torna possível a liberdade da espiritualidade (HEGEL, 2012b; BAVARESCO, 2010).

Em síntese, com Hegel, podemos inferir que a corporeidade-corporalidade se encontra na contradição viva da passagem do Ser à natureza. O corpo é, em si, existente e, de certa forma, posto como exterior à consciência sensível e à Ideia. Porém, nesta exterioridade só é possível ao corpo tornar-se conceito por haver um reconhecimento da existência de si articulado como um todo vivo. Na processualidade da relação consciência/exterioridade surge o processo de identificação particularizada da matéria (enquanto processo de reconhecimento de individualidade) manifestada como um organismo animal e de sua possibilidade de movimento e, INICIALMENTE, suas determinações principais são aquelas encontradas em seu corpo: acaso, carência, necessidade.

Como corpo orgânico, este, então, também é uma manifestação da matéria, da Ideia que se exterioriza e concretiza. Um retorno à idealidade primeira da natureza, que é o retorno à totalidade real (que é o próprio corpo), a própria Vida presente. Mas, agora, como um movimento percebido na consciência do Ser que torna possível a este se tornar/reconhecer como Ser.

Apesar de todos os avanços trazidos, para Lukács, estão presentes no pensamento hegeliano as antinomias do próprio pensamento moderno que decorrem do choque entre duas ontologias que frequentemente operam em oposição recíproca. A articulação de ambas, a despeito de sua oposição, deriva do fato de que uma e outra surgem da mesma realidade em sentido histórico-filosófico.

Lukács afirma que já na $F d E$, Hegel deu um grande passo ao tratar a processualidade do pensamento em sua relação com a objetividade (também entendida como processualidade da realidade), que se apresenta como devir concreto. Engels, segundo Lukács, reconheceu em seu tempo que Hegel foi o primeiro a elevar à condição de conceito e referenciado no ser humano, "[...] a unidade dinâmica do desenvolvimento ontogenético-individual e do desenvolvimento filogenético-genérico" (LUKÁCS, 2012, p. 199).

Por outro lado, há uma segunda ontologia em Hegel - e essa é falsa - em que na recomposição do espírito seja possível a identificação entre a objetividade da realidade e a consciência. Que seria possível o em-si tornar-se integral identificação entre sujeito e objeto e que conduziria a uma compreensão escatológica do desenvolvimento humano, ou seja, sacrificando a processualidade, como se houvesse um fim da história - quando sujeito e objeto, por fim, pudessem ser idênticos.

Assim como Marx, Lukács percebe um outro fator limitador: a acentuação excessiva de o Espírito apoiar-se em si mesmo (mesmo havendo o reconhecimento da formação social do próprio espírito). Acaba-se, assim, por ser uma história do espírito, mesmo que em unidade com a natureza.

Ora, ao que parece, mesmo com seus limites, desde Hegel, a tradição dialética não opera com a separação entre natureza e cultura. Assim, faz-se necessária 
a retomada dessa tradição a fim de enriquecer o debate crítico sobre o corpo na Educação Física. Se Hegel por si já serviria para a contraposição dessa equivocada compreensão de nossa área de que o pensamento moderno em geral dicotomizou cultura e natureza, com Marx teríamos uma resposta mais adensada e fundamental, na qual a natureza assume um estatuto ontológico articulada dialeticamente com a processualidade histórica do ser social, conteúdo este que merece uma outra sistematização à parte.

\section{REFERÊNCIAS}

ANDERY, Maria Amália Pie Ahib et al. Para compreender a ciência: uma perspectiva histórica. Rio de Janeiro: Garamond, 2012.

BARATA-MOURA, José. Hegel e a ontologia. Philosophica, n. 39, p. 7-44, 2012. Disponível em: https://repositorio.ul.pt/bitstream/10451/24260/1/Barata\%20MOura\%207-44.pdf. Acesso em: 03 nov. 2019.

BASSANI, Jaison José; VAZ, Alexandre Fernandez. Sobre o domínio da natureza na filosofia da história de Theodor W. Adorno: uma questão para a educação. Revista Brasileira de Educação [online], v. 16, n. 46, p. 9-32, jul. 2011. DOI: https://doi.org/10.1590/ $\underline{\text { S1413-24782011000100002 }}$

BAVARESCO, Agemir. Princípio lógico universal e subsidiário como estruturante da natureza hegeliana. In: UTZ, Konrad; SOARES, Marly Carvalho (org.). A noiva do espírito: natureza em Hegel. Porto Alegre: EDIPUCRS, 2010. p. 18-36.

CASTELLANI FILHO, Lino. 40 anos de CBCE-de expressão do "Movimento de Renovação Conservadora" à síntese do "Movimento Renovador (Progressista)" da Educação Física/ Ciências do Esporte. In: LARA, Larissa et al. Ciências do Esporte, educação física e produção do conhecimento em 40 anos de CBCE. ljuí: Ed. Unijuí, 2019. p. 65-76. (Coleção Educação Física).

CHAUÍ, Marilena. Convite à filosofia. São Paulo: Ática, 2000.

DAÓLIO, Jocimar. Da cultura do corpo. São Paulo: Papirus, 1995.

DAÓLIO, Jocimar. Educação Física e o conceito de cultura. Campinas: Autores Associados, 2004. (Coleção polêmicas do nosso tempo).

HEGEL, Georg Wilhelm Friedrich. Introdução. In: HEGEL, G. W. F. Enciclopédia das Ciências Filosóficas em Compêndio. 3.ed. São Paulo: Loyola, 2012a. v. 1 - A ciência da lógica.

HEGEL, Georg Wilheim Friedrich. Enciclopédia das Ciências Filosóficas em Compêndio. 3. ed. São Paulo: Edições Loyola, 2012b. v. 2 - Filosofia da natureza.

HEGEL, Georg Wilhelm Friedrich. Ciência da Lógica Petrópolis: Vozes; Bragança Paulista: Editora Universitária São Francisco, 2018. v. 3 - A doutrina do conceito.

HUNGARO, Edson Marcelo. M. A educação física e a tentativa de "deixar de mentir": o projeto de "intenção de ruptura". In: MEDINA, J. P. S. A educação física cuida do corpo... e "mente". 25. ed. Campinas: Papirus, 2010. p. 135-159. 
INWOOD, Michael. Dicionário Hegel. Tradução de Álvaro Cabral. Rio de Janeiro: Jorge Zahar, 1997. (Dicionário de filósofos).

LUKÁCS, György. O jovem Hegel e os problemas da sociedade capitalista. São Paulo: Boitempo, 2018.

LUKÁCS, György. Para uma ontologia do ser social I. São Paulo: Boitempo, 2012.

LUKÁCS, György. Para uma ontologia do ser social II. São Paulo: Boitempo, 2013.

LUKÁCS, György. Prolegômenos para uma ontologia do ser social: questão de princípio/ para uma ontologia tornada possível hoje. São Paulo: Boitempo, 2010.

MARX, Karl. Manuscritos Econômico-Filosóficos. São Paulo: Boitempo, 2010.

MENESES, Paulo. Hegel e a fenomenologia do espírito. Rio de Janeiro: Jorge Zahar, 2003.

MOREIRA, Wagner Wey. Corpo presente num olhar panorâmico. In: MOREIRA, Wagner Wey (org.). Corpo presente, corpo pressente. Campinas: Papirus, 1995. Cap. 1, p. 17- 36. (Coleção Corpo e Motricidade)

NÓBREGA, Therezinha Petrucia da. Corporeidade e educação física: do corpo-objeto ao corpo-sujeito. Natal: EDUFRN, 2009.

ORTIGARA, Vidalcir. Ausência sentida: a determinação ontológica do ser social. 2018. 230 f. Tese (Doutorado em Educação) - Centro de Ciências da Educação, Universidade Federal de Santa Catarina, Florianópolis, 2002.

RANIERI, Jesus. Trabalho e dialética: Hegel, Marx e a teoria social do devir. São Paulo: Boitempo, 2011.

SILVA, Hugo Leonardo Fonseca da. Contribuição à crítica da pedagogia do corpo no trabalho. 2017. 309 f. Tese (Doutorado em Educação) - Faculdade de Educação, Universidade Estadual de Campinas, Campinas, 2017.

ZOBOLI, Fabio. A episteme de cisão corpo/mente: as práxis da educação física como foco de análise. Tese (Doutorado em Educação) - Programa de Pós-Graduação em Educação, UFBA. Salvador, 2007. Disponível em: https://repositorio.ufba.br/ri/bitstream/ ri/10200/1/Tese\%20Fabio\%20zoboli seg.pdf. Acesso em: 3 nov. 2019. 
Abstract: This literature review presents the development of nature and history as categories in Hegel's work. It is understood that more solid indications are found in the philosopher, albeit abstract, of a path towards an ontology of social being. Such a path allows us to observe the logical-conceptual treatment of these categories, as well as to enable the initial comprehension about the body - a topic that is highly present in the Physical Education debate - within this process. We conclude that such development presents a logical-dialectical operation about these categories and about the notion of the body itself. However, it is still limited in its excessively abstract treatment, by focusing on spirit and logic to address these and other categories.

Keywords: Human being. Review. 19th century philosophy. Nature.

Resumen: Resumen: La presente revisión de literatura tiene como objetivo presentar el desarrollo de las categorías naturaleza e historia en la obra hegeliana. Se entiende que en los escritos de este filósofo se encuentran indicios más sólidos, aunque abstractos, de un recorrido hacia una ontología del ser social. Tal recorrido permite observar el tratamiento lógico-conceptual de estas categorías y hace posible la comprensión inicial sobre el cuerpo - tema tan presente en los debates de la Educación Física- en el interior de este proceso. Se concluye que tal desarrollo presenta una operación lógico-dialéctica acerca de estas categorías y sobre la propia noción sobre el cuerpo. Sin embargo, aún presenta límites en cuanto al enfoque excesivamente abstracto al apostar por el espíritu y la lógica para abordar estas y otras categorías.

Palabras clave: Ser humano. Revisión. Filosofía del siglo XIX. Naturaleza. 


\section{LICENÇA DE USO}

Este é um artigo publicado em acesso aberto (Open Access) sob a licença Creative Commons Atribuição 4.0 Internacional (CC BY 4.0), que permite uso, distribuição e reprodução em qualquer meio, desde que o trabalho original seja corretamente citado. Mais informações em: https://creativecommons.org/licenses/by/4.0

\section{CONFLITO DE INTERESSES}

Os autores declararam que não existe nenhum conflito de interesses neste trabalho.

\section{CONTRIBUIÇÕES AUTORAIS}

Marcel Farias de Sousa: participou da concepção e delineamento do estudo, redação do artigo e revisão crítica.

Edson Marcelo Hungaro: participou da orientação, revisão do texto original, redação e revisão final do artigo.

\section{FINANCIAMENTO}

O presente trabalho foi realizado sem o apoio de fontes financiadoras.

\section{COMO REFERENCIAR}

SOUSA, Marcel Farias de; HUNGARO, Edson Marcelo. Natureza e história na filosofia idealista de Hegel: indícios ontológicos para a compreensão do ser e da corporeidade humana. Movimento (Porto Alegre), v.27, p.e27046, jan./dez. 2021. Disponível em: https://seer.ufrgs.br/Movimento/article/view/109297. Acesso em: [dia] [mês abreviado]. [ano]. DOI: https://doi.org/10.22456/1982-8918.109297

\section{RESPONSABILIDADE EDITORIAL}

Alex Branco Fraga*, Elisandro Schultz Wittizorecki, Ivone Job*, Mauro Myskiw*, Raquel da Silveira*

*Universidade Federal do Rio Grande do Sul, Escola de Educação Física, Fisioterapia e Dança, Porto Alegre, RS, Brasil. 